\title{
First report of three species of Trichoderma isolated from the rhizosphere in Algeria and the high antagonistic effect of Trichoderma brevicompactum to control grey mould disease of tomato
}

\author{
Massinissa Hammad ${ }^{1 *}$, Thomas Guillemette ${ }^{2}$, Meriem Alem ${ }^{1}$, Franck Bastide ${ }^{2}$ and Meriem Louanchi ${ }^{1}$
}

\begin{abstract}
Background: Grey mould caused by Botrytis cinerea Pers. (teleomorph Botryotinia fuckeliana (de Bary) Whetzel) is one of the most destructive fungal diseases of Mediterranean crops. In Algeria, few studies have been made on the economic impact of this disease. Nevertheless, it is practically present in all tomato and strawberry greenhouses, as well as in prospected vineyards in the north and south of the country. The complexity of chemical control of this disease has led to search for Trichoderma strains that are effective in biological control.

Results: Fifteen isolates of Trichoderma spp. were obtained from vigorous and healthy plants (tomatoes, strawberries, and vines) rhizosphere, and from a commercial bio-compost (Bio-composte ${ }^{\oplus}$ ), then identified as T. afroharzianum (four isolates), T. gamsii (four isolates), T. longibrachiatum (three isolates), T. atroviride (one isolate), T. brevicompactum (one isolate), T. breve (one isolate), and T. lixii (one isolate) on the basis of DNA sequence analysis of four genes (ITS, tef1, rpb2, and acl1). In vitro biocontrol tests revealed that four Algerian isolates of Trichoderma spp. (TAtC11, TGS7, TGS10, and TBS1) had a high antagonistic activity against B. cinerea, the mycelial growth has been reduced by 62 to $65 \%$ in dual-culture technique, by 62.31 to $64.49 \%$ in volatile compounds test, and a high inhibition of germling growth was recorded by TBS1 isolate with $90.68 \%$ in Culture filtrates test. Biocontrol tests carried out on tomato plants with $T$. brevicompactum (TBS1), T. atroviride (TAtC11), and T. lixii (TLiC8) against B. cinerea (BCT04) showed that TBS1 inoculation significantly reduced the incidence of disease by 64.43 and $51.35 \%$ in preventive and curative treatment, respectively.

Conclusion: The present study revealed the first report of T. brevicompactum, T. breve, and T. lixii in Algeria, and it also contributes to the promotion of the use of native strains of Trichoderma in biological control leading to a better preservation of soil microbial diversity.
\end{abstract}

Keywords: Trichoderma spp., Biological control, Botrytis cinerea, Solanum lycopersicum

\footnotetext{
* Correspondence: m.hammad@edu.ensa.dz

'Laboratoire de Phytopathologie et Biologie Moléculaire, Ecole Nationale

Supérieure Agronomique (ENSA, ex. INA), Rue Hassan Badi, Belfort, El Harrach,

16004 Algiers, Algeria

Full list of author information is available at the end of the article
}

\section{Springer Open}

(-) The Author(s). 2021 Open Access This article is licensed under a Creative Commons Attribution 4.0 International License, which permits use, sharing, adaptation, distribution and reproduction in any medium or format, as long as you give appropriate credit to the original author(s) and the source, provide a link to the Creative Commons licence, and indicate if changes were made. The images or other third party material in this article are included in the article's Creative Commons licence, unless indicated otherwise in a credit line to the material. If material is not included in the article's Creative Commons licence and your intended use is not permitted by statutory regulation or exceeds the permitted use, you will need to obtain permission directly from the copyright holder. To view a copy of this licence, visit http://creativecommons.org/licenses/by/4.0/. 


\section{Background}

Botrytis cinerea Pers, the causative agent of grey mould, is a necrotrophic and polyphagous ascomycete. It has been reported on more than 1400 species of dicotyledonous and monocotyledonous plants and distributed in 586 genera of plants (Elad et al. 2016). This pathogen can infect all parts of the plant, seeds, and other planting material, stems, leaves, flowers, and fruits at the preharvest and post-harvest stages. It is more destructive on mature or senescent tissues and can remains dormant for a long period before causing tissue rot (Williamson et al. 2007). According to Dean et al. (2012), B. cinerea was classified as the second most important fungal plant pathogen in the top 10 list, which can be explained by several factors described by Williamson et al. (2007), the most important are an exceptionally wide host range; the nature of Botrytis epidemics; its genetic plasticity, including adaptation to fungicides.

The chemical control of the grey mould has become difficult because this disease presents a wide genetic variability and a high capacity to acquire resistance against fungicides, classifying it as a high-risk plant pathogen (Shao et al. 2021). To solve this problem, many researchers have proposed alternative methods to control this disease, such as application of biological control agents, plant extracts, minerals, and organic compounds (Nicot et al. 2011).

The genus Trichoderma contains efficient biological control agents (BCA) with a very high antagonistic capacity against a wide range of plant pathogens (Medeiros et al. 2017), through various mechanisms of action, such as parasitism, competition on nutrients, and synthesis of antibiotics (Sood et al. 2020). Although, several species of the genus Trichoderma have been shown to be potentially efficient in controlling $B$. cinerea, only a limited proportion of them have been exploited as biological control agents against this pathogen.

For several decades, the genus Trichoderma has attracted the researchers and industries interest. Approximately $60 \%$ of registered biofungicides based on filamentous fungi have been developed from Trichoderma strains (Verma et al. 2007). Formulation of several commercially available anti-botrytis products was based on isolates of $T$. atroviride, T. harzianum, T. polysporum, and T. viride to control B. cinerea, such as Sentinel ${ }^{\circ}$ formulated with $T$. atroviride strain, LC52 and Trichodex ${ }^{\circ}$ formulated with $T$. harzianum (Nicot et al. 2016). Testing other species of this genus in biocontrol essays should be useful, especially with native species.

The main objective of the present study is to identify native strains of Trichoderma which are effective in biological control of $B$. cinerea, and this could help to minimize the use of pesticide and protecting the environment.

\section{Methods}

Isolation of fungi

Botrytis cinerea isolates

Isolates of $B$. cinerea were obtained from organs with typical symptoms of the grey mould of different host plants (vine, tomato, strawberry), cultivated in the south-eastern (Biskra), north-central (Algiers, Tipaza, Boumerdes), and North-eastern (Bejaia) regions of Algeria. Single-spore was prepared for each isolate and deposited on Petri dishes containing PDA medium. After 5 days of incubation under continuous white light and at a temperature of $20^{\circ} \mathrm{C}$, monosporic isolates were stored at $-20{ }^{\circ} \mathrm{C}$ in $20 \%(\mathrm{v} / \mathrm{v})$ glycerol.

\section{Trichoderma sp. isolates}

Sampling was carried out in different geographic regions in the north-central of Algeria (Tipaza, Boumerdes, and Algiers). Trichoderma isolates were isolated from the rhizosphere of vigorous and healthy plants (tomatoes, strawberries, and vines), and also from a commercial bio-compost (Bio-composte ${ }^{\odot}$. Soil and compost (10 g) were dried, ground into powder, and dissolved in $90 \mathrm{ml}$ of sterile distilled water then vortexed in order to homogenize the mixture. Several dilutions were elaborated to $10^{-9}(1 \mathrm{v} / 9 \mathrm{v})$. One $\mathrm{ml}$ of each dilution was spread evenly onto Petri dishes containing the PDA medium (potato dextrose agar) with $0.05 \mathrm{~g}$ streptomycin to reduce bacterial contaminations. After 8 to 10 days of incubation at $22 \pm 1{ }^{\circ} \mathrm{C}$, the fungal colonies with typical characteristics of Trichoderma spp. were isolated and purified by single spore cultures.

Pathogenicity test The pathogenicity of $B$. cinerea isolates was tested using the technique described by Schüepp and Küng (1978) and modified as proposed by Vignutelli et al. (2002) on half apples of the Golden Delicious variety. The surface of apples was sterilized with ethanol $70 \%$ and then cut in half, on each half three perforations were made using an 8-mm-diameter punch. The realized holes were filled with mycelial discs of the pathogen of the same diameter in direct contact with the apple flesh. For the control, sterile PDA discs were used. The two opposite diameters of the rot lesions were measured after 3 days of incubation in the dark at $20 \pm 1{ }^{\circ} \mathrm{C}$.

DNA extraction, PCR and sequencing of Trichoderma spp Genomic DNA was extracted from 7- to 10-day old mycelial growth on potato dextrose agar (PDA) medium following the protocol from Goodwin and Lee (1993). For the molecular identification of the isolates, the PCR was carried out on 4 genomic regions: (i) internal transcribed spacer (ITS) regions 1 and 2 was amplified using primers ITS1 and ITS4 (White et al. 1990). (ii) A fragment of approximately $1.2 \mathrm{~kb}$ from the gene encoding 
the translation elongation factor $1(T E F 1 \alpha)$ was amplified using primer pairs EF1-728F (Carbone and Kohn 1999) and TEF1LLErev (Jaklitsch et al. 2005). (iii) A fragment of about $1.1 \mathrm{~kb}$ from the gene encoding RNA polymerase II subunit B ( $r p b 2)$ was amplified with primer pairs fRPB2-5f and fRPB2-7cr (Liu et al. 1999). (iv) A fragment of $0.9 \mathrm{~kb}$ encoding the largest ATP citrate lyase subunit (acl1) was amplified with primers acl1-230up and acl1-1220low (Gräfenhan et al. 2011) (Table 1). The PCR mixtures were prepared with $\mathrm{Go}^{\mathrm{Taq}}{ }^{\circ}$ Flexi, containing $0.5 \mu \mathrm{l}$ of each primer $(20 \mu \mathrm{mol}), 1.5 \mu \mathrm{l}$ of $\mathrm{MgCl} 2$ solution $(25 \mathrm{mM})$, $0.5 \mu \mathrm{l}$ of dNTP $(0.2 \mathrm{mM}$ each dNTP), $5 \mu \mathrm{l}$ of $5 \times$ Green Go $\mathrm{Taq}^{\circ}$ Flexi Buffer and $15.9 \mu \mathrm{l}$ of steriledistilled water and $0.1 \mu \mathrm{l}$ of Taq DNA polymerase (5 units $/ \mu \mathrm{l}$ ) and $1 \mu \mathrm{l}$ of DNA suspension for a total volume of $25 \mu \mathrm{l}$. PCR program for ITS and tef1 gene start with initial denaturation step of $3 \mathrm{~min}$ at $95{ }^{\circ} \mathrm{C}$, followed by 35 cycles of 30 seconds at $94{ }^{\circ} \mathrm{C}$; hybridation at $58{ }^{\circ} \mathrm{C}$ for $30 \mathrm{~s}$ and an extension at $72{ }^{\circ} \mathrm{C}$ for $1 \mathrm{~min}$, and a final extension step of $10 \mathrm{~min}$ at $72{ }^{\circ} \mathrm{C}$. Finally, a refrigeration step at $4{ }^{\circ} \mathrm{C}$. rpb2 and acl1 gene annealing temperature has been changed for both at $55{ }^{\circ} \mathrm{C}$.

Nucleotide and phylogenetic analysis of Trichoderma sequences Sequences were analyzed by comparison with all sequences of Trichoderma spp. available at the GenBank of National Center for Biotechnology Information (NCBI, https://www.ncbi.nlm.nih.gov/) and the International Subcommission on Trichoderma and Hypocrea Taxonomy (ISTH, www.isth.info) (Druzhinina et al. 2005; Kopchinskiy et al. 2005). Alignments of Algerian isolates sequences and the reference sequences of extype strains described by several authors (Bissett et al. 2015; Jaklitsch and Voglmayr 2015; Chen and Zhuang 2017) were performed with Clustalw program implemented in MEGA7. Phylogenetic trees were designed for the four genes studied using the neighbor-joining method (MEGA7) with 1000 bootstraps.

Table 1 Primer sequences

\begin{tabular}{lll}
\hline Gene & Primer name & Sequences \\
\hline ITS & ITS1 & 5'-TCGGTAGGTGAACCTGCGG-3' \\
& ITS4 & 5'-TCCTCCGCTTATTGATATGC-3' \\
acl1 & acl1-230up & 5'-AGCCCGATCAGCTCATCAAG-3' \\
& acl1-1220low & 5'-CCTGGCAGCAAGATCVAGGAAGT-3' \\
tef1 & EF1-728f & 5'-CATCGAGAAGTTCGAGAAGG-3' \\
& TEF1LLErev & 5'-AACTTGCAGGCAATGTGG-3' \\
rpb2 & fRPB2-5f & 5'-GAYGAYMGWGATCAYTTYGG-3' \\
& fRPB2-7cr & 5'-CCCATRGCTTGYTTRCCCAT-3' \\
\hline
\end{tabular}

\section{Antagonistic activity of Trichoderma spp. against $B$. cinerea}

i. Dual-culture technique

In vitro confrontation test consists of placing two explants of $8 \mathrm{~mm}$ diameter of the antagonist agent (Trichoderma spp.) and the pathogen (B. cinerea) in the same Petri dish containing PDA medium. The explants were taken with a sterile punch from 5- to 7-day old culture. The two explants of the pathogen and the antagonist agent were placed simultaneously along a diametrical axis, leaving a distance of $5 \mathrm{~cm}$ between them and about $2 \mathrm{~cm}$ from the extremity of the Petri dish. The control contains only the explants of $B$. cinerea isolates. Petri dishes were incubated 10 days in the dark at $25^{\circ} \mathrm{C}$. Four repetitions were carried out for each treatment. The percentage inhibition of radial growth of pathogens (PIRG P) was computed compared to a control (Ezziyyani et al. 2004).

ii. Effect of volatile compounds of Trichoderma on the mycelial growth of $B$. cinerea

The effect of volatile compounds on the mycelial growth was evaluated by the method described by Olivier and Germain (1983). Explants of $8 \mathrm{~mm}$ diameter taken from the 3-day-old cultures of each pathogen and antagonist were placed in the center of the Petri dishes containing PDA medium. An assembly was carried out by superimposing the two Petri dishes without lids, Trichoderma spp. was placed on the bottom and B. cinerea at the top. To avoid loss of volatile substances, the junction was ensured by parafilm ${ }^{\bullet}$ Petri dishes containing the pathogen on the top and PDA without antagonist on the bottom used as control. Three replicates were used for each combination and the experiment was repeated 3 times. The 2 opposite diameters of the $B$. cinerea colonies were measured every day for 4 days of incubation in the dark at $25^{\circ} \mathrm{C}$. Evaluation of inhibition by Trichoderma spp. was estimated by calculating the percentage inhibition of mycelial growth as compared to a control (Hmouni et al. 1996).

\section{iii. Effect of culture filtrate of Trichoderma spp. on mycelial growth of $B$. cinerea}

The effect of culture filtrates of 15 isolates of Trichoderma spp. was evaluated against 3 isolates of $B$. cinerea selected on the basis of their high pathogenicity. To achieve this experiment, 10 mycelial explants of $8 \mathrm{~mm}$ diameter were collected from Trichoderma cultures of 7 to 10-day-old and deposited in $100 \mathrm{ml}$ of PDB medium in $250 \mathrm{ml}$ conical flask, and incubated at $28{ }^{\circ} \mathrm{C}$ for $72 \mathrm{~h}$ under continuous agitation. The culture filtrate was first 
filtered through a filter paper to remove mycelium and a second filtration through Millipore membranes of 0.20 $\mu \mathrm{m}$ diameter to remove spores, and then stored at $4{ }^{\circ} \mathrm{C}$. $B$. cinerea spore suspensions were prepared from cultures of 7-10 days old. The concentration was adjusted to $10^{6}$ spores $/ \mathrm{ml}$ by using the malassez cell.

To study the antifungal effect of Trichoderma spp. culture filtrates on the mycelial growth of B. cinerea, a final volume of $1 \mathrm{ml}$ was prepared as follows: Trichoderma spp. culture filtrate with $B$. cinerea suspension containing $800 \mu \mathrm{l}$ PDB, $100 \mu \mathrm{l}$ of Trichoderma spp. culture filtrate, and $100 \mu \mathrm{l}$ of $B$. cinerea spore suspension. Control without B. cinerea contained $800 \mu \mathrm{l}$ PDB, $100 \mu \mathrm{l}$ of Trichoderma spp. culture filtrate, and $100 \mu \mathrm{l}$ ultrapure water. Control with B. cinerea contained $900 \mu \mathrm{l}$ PDB and $100 \mu \mathrm{l}$ of $B$. cinerea spore suspension. The preparations were filled in 96-well plates $(300 \mu \mathrm{L} /$ well). The plates were covered and sealed to avoid contamination. Four independent biological replicates were performed; each replicate included 3 technical repetitions for each sample in the same plate. Mycelial growth was automatically recorded every 10 min during the 33 -h incubation at $25{ }^{\circ} \mathrm{C}$ by nephelometry reader equipped with a 635nm laser (NEPHELOstar ${ }^{\circ}$ Galaxy, Offenburg, Germany). During incubation, the microplates were shaken at 175 rpm for 5 min every 10 min (Joubert et al. 2010).

Data were exported from Nephelostar Galaxy software in ASCII format and further analyzed with Microsoft Excel 2016 (version 16.0.12827.20268) and R3.4.1 (R Core Team 2020). The lag phase and the maximal growth rate variables were calculated according to the method described by Joubert et al. (2010). The initial relative nephelometric unit (RNU) value was calculated as the average of the 3 initial measurements and then subtracted from each curve value. For each point on the curve, a slope was calculated using measurements that were taken $2 \mathrm{~h}$ before and $2 \mathrm{~h}$ after this time. The lag phase was defined as the time required to obtain a slope value of 1 and the maximal growth rate was defined as the highest slope.

In situ biocontrol assays in tomato plants To control grey mould disease caused by the most virulent isolate of B. cinerea (BCT04), the potential preventive effect of three isolates of Trichoderma (TBS1, TAtC11, TLiC8) was tested in situ on tomato plants cv. "KAWA" of 28days old. The tomato plants were grown under a greenhouse in pots of $12 \mathrm{~cm}$ diameter, containing a mixture of commercial soil, sterile soil, and sterile sand $(\mathrm{v} / \mathrm{v} / \mathrm{v})$. An inoculation with a suspension of $10^{5}$ spores $/ \mathrm{ml}$ of $B$. cinerea was performed into the pots and after $24 \mathrm{~h}$ by spraying with a suspension of $10^{6}$ spores $/ \mathrm{ml}$ of Trichoderma spp.
To evaluate the potential curative effect, the same method was applied, except that inoculation with a suspension of $10^{5}$ spores $/ \mathrm{ml}$ of $B$. cinerea was carried out 24 $\mathrm{h}$ before the treatment with suspension of Trichoderma spp. $\left(10^{6}\right.$ spores $\left./ \mathrm{ml}\right)$. Approximately $5 \mathrm{ml}$ of conidial suspension per plant of $B$. cinerea and Trichoderma spp. was used. The positive control was constituted only by inoculation with a suspension of $B$. cinerea $\left(10^{5}\right.$ spores $\left./ \mathrm{ml}\right)$. Ten plants were used for each combination of B. cinerea/Trichoderma spp. and for the positive control. The experiment was conducted for a week and repeated 3 times.

A scale described by You et al. (2016) ranging from 0 to 4 , in which 0 indicates that the leaflet is apparently healthy, while $1,2,3$, and 4 indicate percentages of necrotic lesion of 1 to $25,26-50 \%, 51-75 \%$, and $76-100 \%$ of the total leaflet surface area, respectively. Disease development on plants was assessed as a function of the number of diseased leaflets relative to the total number of leaflets. Disease incidence and biocontrol efficiency were calculated for each treatment, using the formulas described by Xue et al. (2009).

\section{Statistical analysis}

To evaluate the biocontrol effect of Trichoderma spp. isolates on the development of $B$. cinerea, the data were subjected to analysis of variance (ANOVA), and when the data were not normally distributed (Shapiro normality test-Wilks, $P<0.05$ ), a non-parametric variance analysis (Kruskal-Wallis test) was performed, using Statistical Package for R3.4.1. (R Core Team 2020).

\section{Results}

\section{B. cinerea isolation and pathogenicity tests}

Thirty isolates of $B$. cinerea were obtained from tomato plants (10 isolates), vine plants (10 isolates), and strawberry plants (10 isolates). The survey was carried out over two successive years 2016 and 2017, in the northcentral and south-eastern region of Algeria (Table S1; Supplementary data 1). Pathogenicity tests on halfapples revealed significant differences among the different isolates tested (Kruskal-Wallis test was done on diameters of the rot lesions, $X^{2}=114.14, \mathrm{df}=29, P$ value $<0.05)$. The most virulent isolate of each culture was chosen for the biocontrol tests, from vine (BCV02), tomato (BCT04), and BCFr11 (strawberry) (Fig. 1).

\section{Trichoderma identification and phylogenetic analysis}

Fifteen isolates with macroscopic and microscopic characteristics of the genus Trichoderma were isolated from the different samples collected. Ten isolates were obtained from tomato; strawberries, vines rhizosphere and 5 isolates were obtained from Bio-compost ${ }^{\circ}$. Four genomic regions from all of these isolates were sequenced (Table S2; Supplementary data 1). 


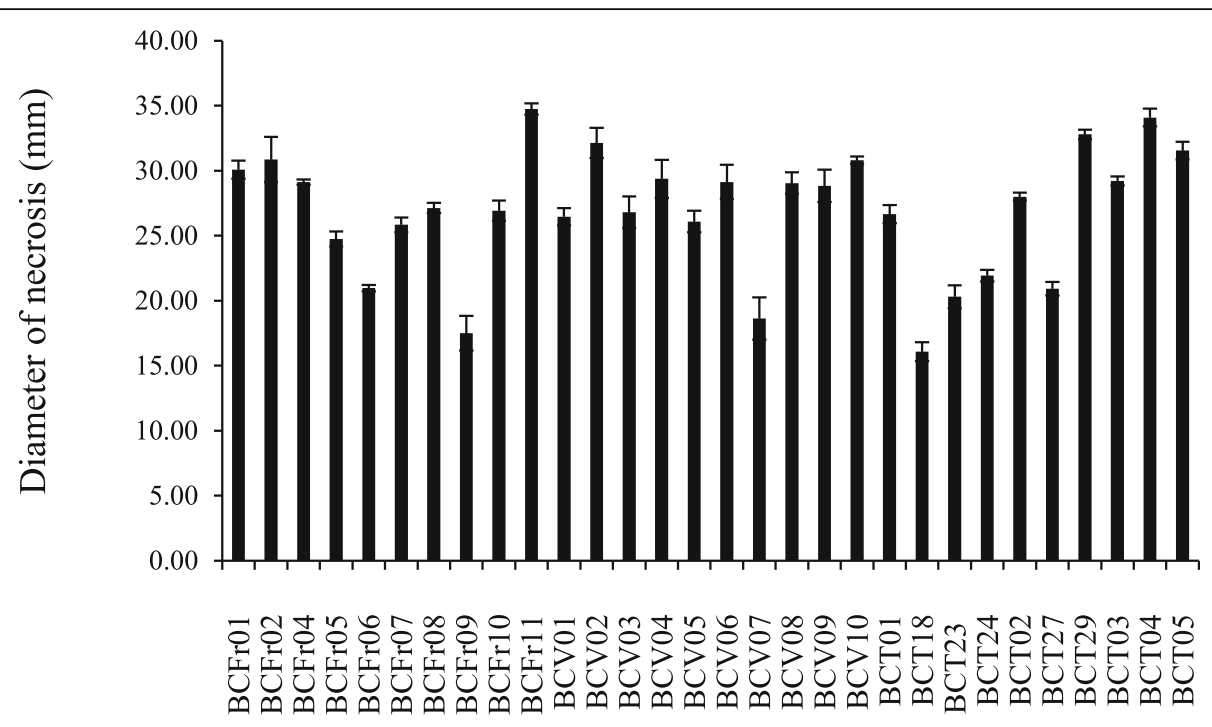

Strains of B. cinerea

Fig. 1 Pathogenicity test of $B$. cinerea isolates on half apples of the variety Golden Delicious, after incubation for 3 days at $21{ }^{\circ} \mathrm{C}$. The values are the mean of the technical and biological replicates $( \pm \mathrm{SE})$

BLAST search of the sequences obtained during this work was performed and also, they were submitted to the ISTH TrichOKey (http://isth.info/tools/molkey/ index.php) and TrichoBlast programs (http://isth.info/ tools/blast/index.php). The results with the highest similarity percentages to the 15 sequences obtained in this study were selected for species identification.

Results revealed that the isolates TAS2, TAS4, TAS5, and TAS8 belong to Harzianum clade, and presented a (99\%) of nucleotide identity with the reference sequences of the specie T. afroharzianum, for the tef1 (KP008850) and $r p b 2$ genes (FJ442691) and (96\%) with the species $T$. simmonsii, for acl1 gene (KJ665182). The isolate TBeC1 had a (99\%) of nucleotide identity with the reference sequences of the species T. breve, of the clade Harzianum for the tef1 (KY688046) and rpb2 genes (KY687983) and (97\%) with the species T. guizhouense for acl1 gene (KJ665030). The TLiC8 isolate present a (99\%) of nucleotide identity with the reference sequences of the species T. lixii, of the clade Harzianum for the tef1 (FJ716622) and rpb2 and (98\%) with the species T. atrobrunneum for acl1 gene (KJ664949). Using ITS sequences, they were identified as $T$. harzianum/H. lixii and showed $(100 \%)$ of similarity to several species of the Harzianum clade.

Isolates TLS6, TLC2, and TLC4 showed (99\%) of nucleotide identity to the reference sequences of $T$. longibrachiatum, for tef1 (JQ685867), rpb2 (JQ685883), and acl1 (KJ665057). However, for the ITS gene, they were identified as T. longibrachiatum and showed a percentage of $(100 \%)$ nucleotide identity with several species belonging to the Longibrachiatum clade. The isolates
TGS11 and TGS13 revealed (99\%) of similarity to the reference sequences of $T$. gamsii, belonging to Viride clade based on the tef1 sequence (EF488134). In addition, the TGS7 and TGS10 isolates revealed (99\%) of nucleotide identity with the reference sequence of $T$. gamsii for the acl1 gene (KJ665025). TAtC11 isolate revealed (99\%) of similarity to the reference sequences of $T$. atroviride, clade Viride for tef1 (MH176994), rpb2 (FJ860518), and acl1 (KJ664952), while for the ITS gene, they were identified as species belonging to the clade Viride with $(100 \%)$ nucleotide identity with several species of this clade. TBS1 showed (99\%) of nucleotide identity with the reference sequences of $T$. brevicompactum species, for the tef 1 sequence (EU338292, EU338283) and for ITS sequence, it was identified as T. brevicompactum and revealed (100\%) nucleotide identity with several species of the Brevicompactum clade.

Phylogenetic trees were designed for each of the 4 gene regions studied, with the sequences of the $15 \mathrm{Al}$ gerian isolates and the reference sequences downloaded from GenBank. Thereby, the trees of the tef1, rpb2, and acl1 genes revealed the same phylogenetic distribution of the Algerian sequences obtained during this work and the presence of 4 distinct clades (Fig. 2) (Fig. S1, S2, S3; Supplementary data 2). The first one was the clade Harzianum, containing the isolates TAS2, TAS4, TAS5, TAS8, TBeC1, and TLiC8, the first 4 isolates were closely related to the reference strain of specie $T$. afroharzianum (G.J.S. 04-186), the $\mathrm{TBeC} 1$ isolate to the reference strain of specie T. breve (HMAS:248844) and the TLiC8 isolate to the reference strain of specie $T$. lixii (G.J.S. 97-96 = CBS 110080). The second was the 


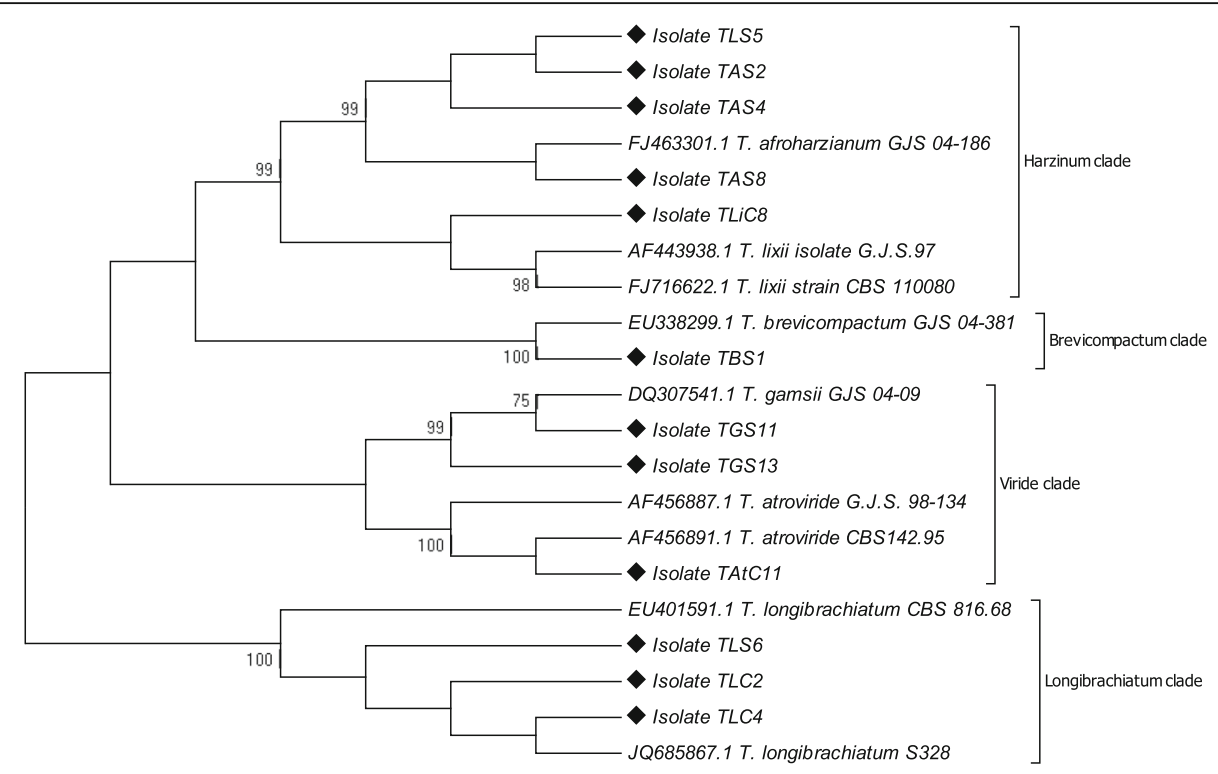

Fig. 2 Neighbor-joining phylogenetic tree of Trichoderma spp. constructed with tef1 sequences. Bootstrap support values higher than $75 \%$ from 1000 replicates are indicated on relevant tree branches

Longibrachiatum clade, containing TLS6, TLC2, and TLC4 isolates, which were closely related to the reference strain of T. longibrachiatum (S328, CBS 816.68) for the 3 trees. The third clade was Viride, including TGS7, TGS10, TGS11, TGS13, and TAtC11 isolates; the isolates TGS7, TGS10, TGS11, and TGS13 are closely related to the reference strain of T. gamsii (GJS 04-09) and the TAtC11 isolate to the reference strains of T. atroviride (S360, CBS 142.95). The fourth was the clade Brevicompactum in which the isolate TBS1 belongs, and was closely linked to the reference strain of $T$. brevicompactum (CBS $109720=$ G.J.S.04-381). However, the ITS tree revealed the same genetic distribution for clades, but the species were placed differently, thus making identification at the species level almost impossible (Fig. S1; Supplementary data 2).

\section{In vitro antagonistic tests Dual-culture technique}

In the dual-culture test, the 15 isolates of Trichoderma inhibited the mycelial growth of the 3 most virulent isolates of $B$. cinerea as compared to the control without Trichoderma spp. with a range varying from 53 to $65 \%$ on PDA medium (Fig. 3). For each B. cinerea isolate, a

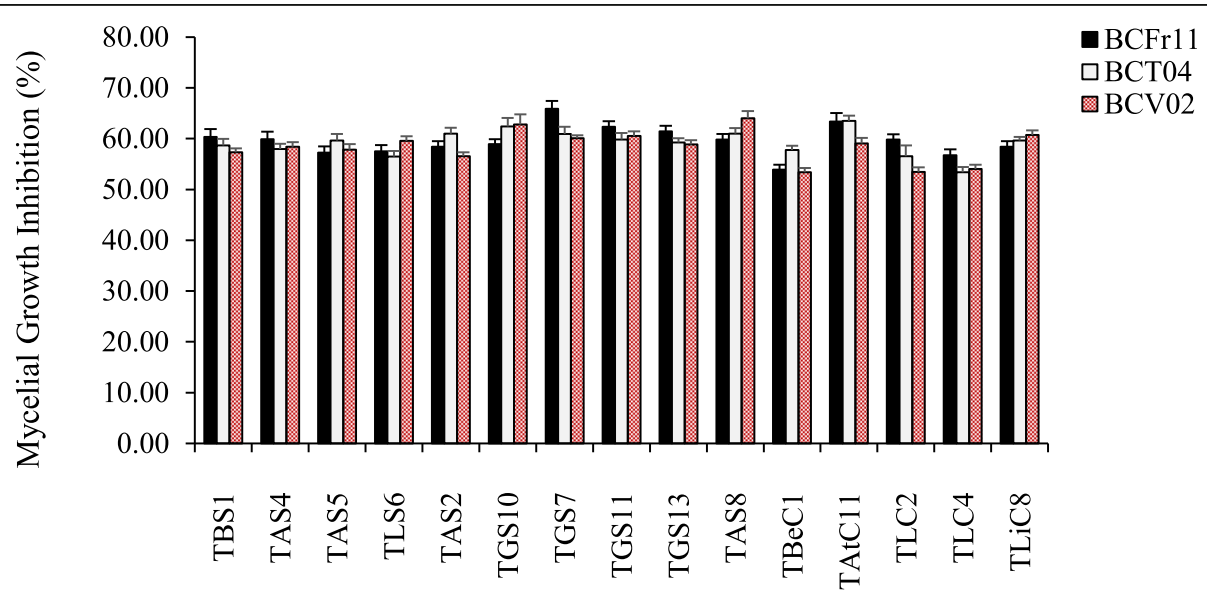

Strains of Trichoderma spp.

Fig. 3 Mycelial growth inhibition of three isolates of B. cinerea caused by 15 isolates of Trichoderma spp. revealed by the dual-culture test. Values are the mean of technical and biological replicates $( \pm S E)$ 
significant Trichoderma effect was observed (ANOVA was performed on the percentage inhibition of mycelial growth, $F=82.33$, df $=14,30, P<0.0001$ for BCV02, and $F=49.68, \mathrm{df}=14,30, P<0.0001$ for BCT04 and $F=49.29, \mathrm{df}=14,30, P<0.0001$ for BCFr11). The higher inhibition rate was recorded for T. gamsii (TGS7 isolate), T. atroviride (TAtC11 isolate) (Fig. S4; Supplementary data 3) and T. longibrachiatum (TAS8 isolate), which varied from 62 to $65 \%$. T. longibrachiatum (TLC2 and TLC4 isolates) and T. breve ( $\mathrm{TBeC} 1$ isolate) gave the lowest inhibition rates, ranging from 53 to $57 \%$.

\section{Effect of volatile compounds of Trichoderma on the mycelial growth of $B$. cinerea}

Results revealed a significant difference in the effect of volatile substances produced by Trichoderma isolates on mycelial growth of the tested $B$. cinerea isolates (Kruskal-Wallis test was performed on the percentage inhibition of mycelial growth, $\chi^{2}=$ 43.018, $\mathrm{df}=14, p$ value $<0.05$ for BCFr11, $\chi 2=$ 42.477, $\mathrm{df}=14, P$ value $<0.05$ for $\mathrm{BCV} 02$ and $\chi 2=$ 43.262, $\mathrm{df}=14, P$ value $<0.05$ for BCT04) (Fig. 4). Volatile substances emitted by T. gamsii (TGS7 isolate) and T. atroviride (TAtC11 isolate) reduced mycelial growth of $B$. cinerea isolates by 64.49 and $62.31 \%$, respectively, than the control (Fig. S5; Supplementary data 3 ). The lowest growth inhibition rate (18.41 and 19.72\%) were reported for T. longibrachiatum (isolate TLS6) and T. afroharzianum (isolate TAS4), respectively.

\section{Culture filtrates}

A significant culture filtrates effect was observed for the 3 strains of $B$. cinerea (Kruskal-Wallis test was done on germling growth inhibition, $X^{2}=33.407, \mathrm{df}=14, P$ value $<0.05$ for BCFr11, $X^{2}=41.267, \mathrm{df}=14, P$ value $<0.05$ for BCV02 and $\chi^{2}=53.082, \mathrm{df}=14, P$ value $<0.05$ for BCT04) (Fig. 5). The best percentages of inhibition were recorded from the filtrates of $T$. brevicompactum (isolate TBS1) (90.68\%) and T. atroviride (TAtC11 isolate) (68.72\%), suggesting a high antifungal effect of these filtrates. While filtrates from the rest of Trichoderma spp. isolates revealed stimulation of germling growth for the 3 tested B. cinerea isolates, as compared to the control. Percentages of stimulation ranged from 4.25 to $46.31 \%$, the highest percentage of stimulation being found for $T$. longibrachiatum (TLS6 and TLC2 isolates).

\section{In situ test}

The effect of spore suspension treatments of T. atroviride (TAtC11 isolate), T. brevicompactum (TBS1 isolate), and T. lixii (TLiC8 isolate) on the incidence of disease caused by $B$. cinerea (BCT04 isolate), in tomato cv. "KAWA" revealed significant differences. Biocontrol activity was observed for the 3 tested Trichoderma isolates for preventive and curative treatments. However, the highest percentages of disease control (DC) were recorded for $T$. brevicompactum (TBS1) with $64.43 \pm$ $4.34 \%$ in preventive treatment and $51.35 \pm 1.56 \%$ in curative treatment, while the lowest percentages of disease control (DC) were recorded for T. lixii (TLiC8) with $34.19 \pm 4.54 \%$ in preventive treatment and only $28.46 \pm$ $8.93 \%$ in curative treatment. Based on these results, $T$.

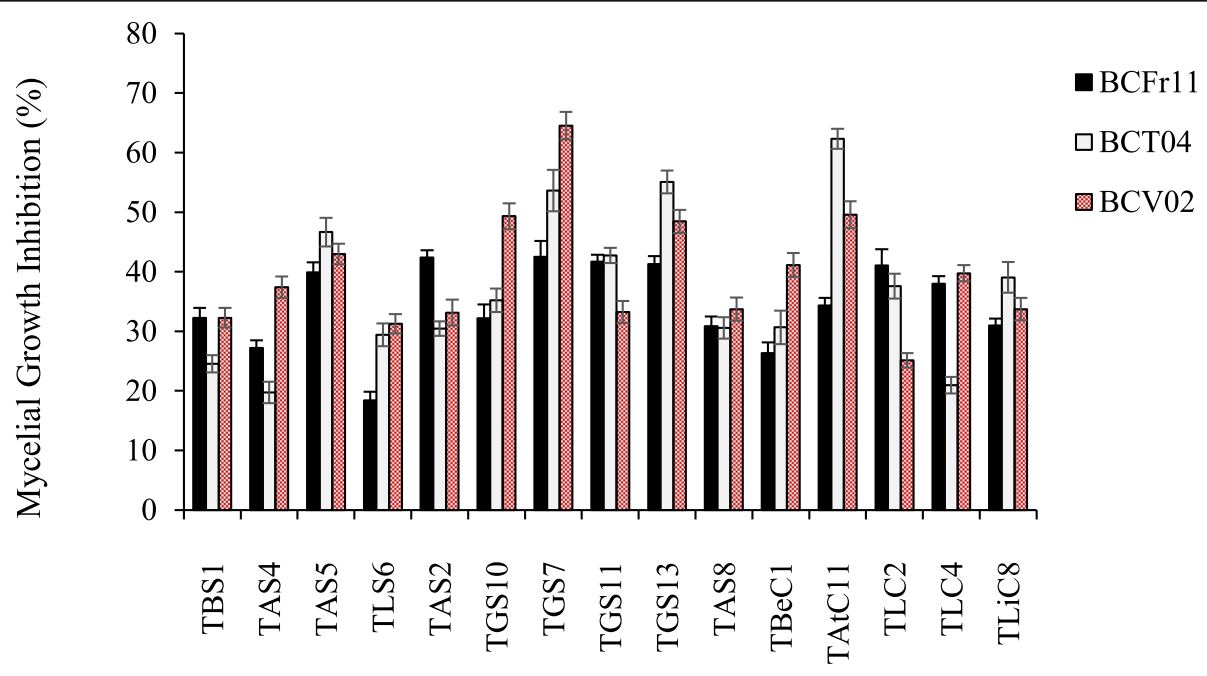

Strains of Trichoderma spp.

Fig. 4 Mycelial growth inhibition of three isolates of $B$. cinerea caused by volatile compounds produced by 15 isolates of Trichoderma spp. Values are the mean of technical and biological replicates $( \pm \mathrm{SE})$ 


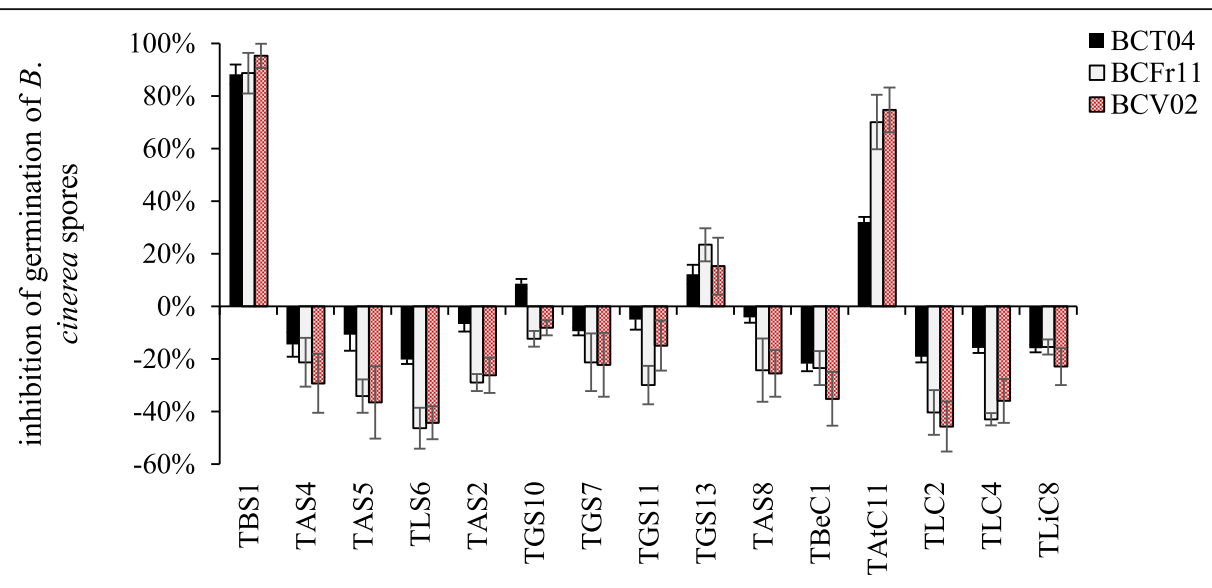

Strains of Trichoderma spp.

Fig. 5 Inhibition effect of culture filtrates from 15 isolates of Trichoderma spp. on spore germination and germling growth of three isolates of $B$. cinerea. Values are the mean of technical and biological replicates $( \pm \mathrm{SE})$

brevicompactum (TBS1) was the most effective isolate for the control of grey mould on tomatoes caused by $B$. cinerea (BCT04) (Fig. 6).

\section{Discussion}

$B$. cinerea is recognized as a high-risk plant pathogen, with global economic losses exceeding 2 billion Euros per year (Dean et al. 2012). At this day, the control of this plant pathogen is mainly chemical, but due to its wide genetic variability and adaptability, acquired resistance has been observed with all fungicides used against grey mould (Shao et al. 2021). This has prompted the scientific community to move towards alternative control methods, such as biological control, with the use of antagonistic agents (Nicot et al. 2011).

Obtained results of pathogenicity test of 30 isolates of B. cinerea on half apples revealed significant differences in aggressiveness. This is consistent with the results of several studies which showed that isolates of $B$. cinerea did not exhibit the same degree of aggressiveness on the same host plant (Decognet et al. 2009). Some strains of the genus Trichoderma are sought for their highest potential in biological control and in stimulation of the natural plant defenses by various mechanisms (Hermosa

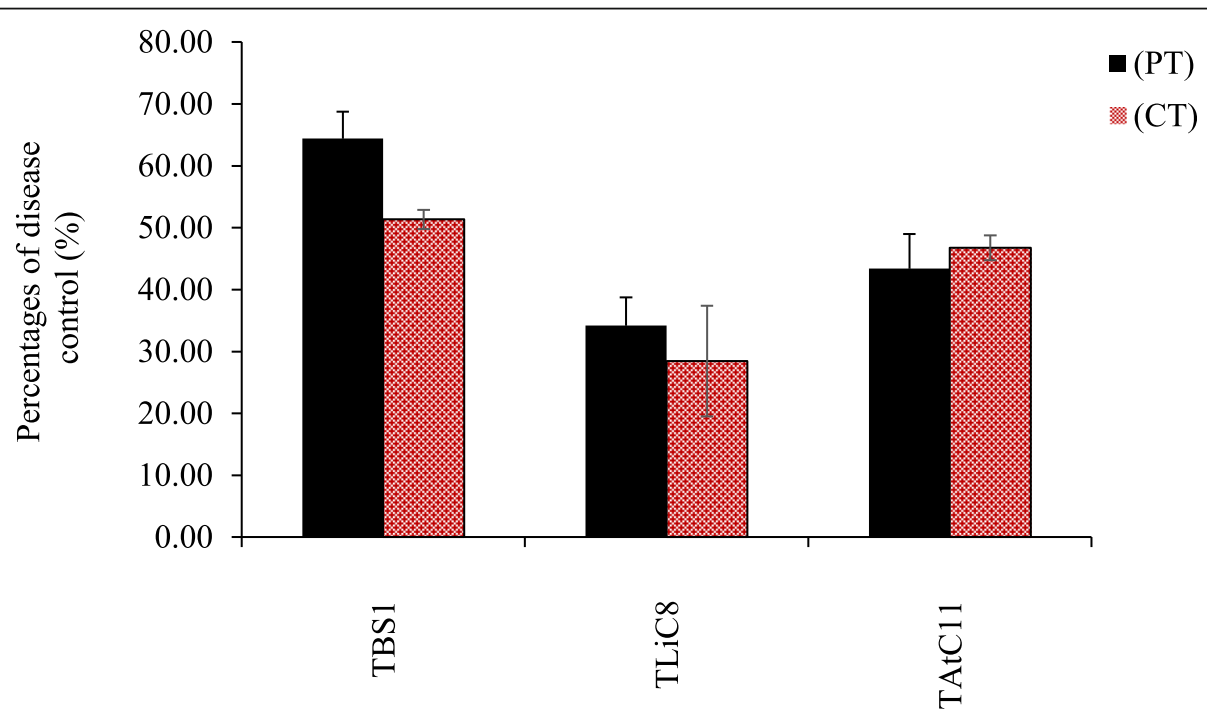

Traitements

Fig. 6 Protection of tomato plants against B. cinerea isolate (BCT04) revealed by three isolates of Trichoderma spp. (TBS1, TAtC11, TLiC8). Tests were carried out on 30-day-old tomato plants (Kawa variety). Two modalities of treatment were applied, preventive treatment (PT), and curative treatment $(\mathrm{CT})$. The values correspond to the mean of 30 replicates $( \pm \mathrm{SE})$ 
et al. 2012). So, they are used in the formulation of many commercial products for biological control and/or plant bio-stimulation (Samuels and Hebbar 2015). In this study, native strains that were isolated from agricultural soils in north-central of Algeria were chosen to use, in order to avoid any ecological disturbance of the soil microbial biodiversity. Furthermore, meticulous identification and characterization must be carried out before any use (Galarza et al. 2015).

In the present work, 15 isolates were clearly identified as corresponding to 7 species of Trichoderma distributed in 4 different clades. Until now, only 8 species of Trichoderma were reported in Algeria: T. harzianum/H. lixii, T. asperellum, T. ghanense, T. atroviride, T. longibrachiatum, $T$. viride, T. atrobrunneum, and T. afroharzianum (Keddad and Bouzenad 2019; Haouhach et al. 2020). Based on these results, this was the first report of the presence of $T$. brevicompactum, T. breve, and T. lixii in Algeria. In this study, the ability of Algerian isolates of Trichoderma to control grey mould disease was demonstrated. Isolates showed high efficiency in biological control were selected on the basis of in vitro tests. Consequently, three isolates were chosen for the in situ biocontrol test, and two of them, T. brevicompactum isolate TBS1 and T. atroviride TAtC11, showed an interesting inhibitory effect of $B$. cinerea growth through culture filtrate test and the third isolate T. lixii (TLiC8), one of the less studied in biological control was used to test its biocontrol efficiency.

The radial mycelial growth inhibition of $B$. cinerea in dual-culture technique varied from 54 to $64 \%$, indicating the high competitiveness of Trichoderma species (Benítez et al. 2004). The reduction in nutrient concentrations generally leads to a reduction in conidia germination and to a slower growth of pathogen germlings (Nassr and Barakat 2013). However, the best results were observed with the isolates of T. gamsii (TGS7, TGS10), $T$. atroviride (TAtC11), and T. afroharzianum (TAS8). These three species have been described by several studies for their ability to control grey mould and other plant fungal diseases (Redda et al. 2018).

The antagonistic effect of the volatile compound revealed that, T. gamsii (TGS7) and T. atroviride (TAtC11) showed an important effect compared to the other studied isolates. A powerful odor of coconut aroma was found in these two isolates, which may suggest that volatile inhibitory effect of T. gamsii (TGS7) and T. atroviride (TAtC11) against $B$. cinerea may be due to pyrone 6-pentyl-2H-pyran-2-one 'coconut aroma' commonly produced by Trichoderma spp. (Vinale et al. 2008). The antifungal activity of pyrone 6-pentyl-2H-pyran-2-one was shown in vitro and in vivo against B. cinerea by Pezet et al. (1999).

The highest antifungal activity of culture filtrates on $B$. cinerea spore germination and germling growth was observed by $T$. brevicompactum (isolate TBS1), which may be explained by the ability of this species to produce large quantities of trichothecen, trichodermin, and harzianum (Klaiklay et al. 2019). Several authors have reported the inhibitory activity of these secondary metabolites against plant pathogenic fungi, adding this species to the list of biological control agents (Shentu et al. 2014). It was also found that 12 isolates of Trichoderma spp. did not inhibit the germination of $B$. cinerea spores by culture filtrates, but stimulated it. These results can be explained either by the inability of these isolates to synthesize metabolites with fungicidal and/or fungistatic effect against $B$. cinerea isolates or by the resistance of $B$. cinerea isolates to the metabolites secreted by Trichoderma isolates. Previous studies have demonstrated that B. cinerea can develop resistance to antibiotics produced by the biological control agents (Fillinger et al. 2012).

Greenhouse assays were carried out on "KAWA" tomato plants with the most aggressive isolate of $B$. cinerea (BCT04). The most important reduction in disease incidence was observed in T. brevicompactum (isolate TBS1). Results were very promising in both preventive and curative treatments. For this reason, T. brevicompactum (isolate TBS1) can be highly recommended for the development of commercial bio-fungicides for the integrated management of grey mould. T. atroviride (TAtC11 isolate) was less effective in biocontrol in planta test as compared to the results obtained from the in vitro biocontrol test. As for $T$. lixii (TLiC8 isolate), the results were similar to those obtained in in vitro tests; this isolate seems unable to control grey mould.

\section{Conclusion}

The possibility to control the $B$. cinerea disease using Algerian isolates was obtained by the rhizosphere of the host plants. These results also confirmed the effectiveness of native strains in biological control, leading to a better preservation of soil microbial diversity, because the strains already exist in the soil microbial complex. T. brevicompactum (isolate TBS1) was a very interesting species in biological control of tomato grey mould disease.

\section{Abbreviations \\ BCA: Biological control agents; ISTH: International Subcommission on Trichoderma and Hypocrea Taxonomy; NCBI: National Center for Biotechnology Information; PDA: Potato dextrose agar; PDB: Potato dextrose broth; PIRGP: The percentage inhibition of radial growth of pathogens; RNU: Relative nephelometric unit; DC: Disease control}

\section{Supplementary Information}

The online version contains supplementary material available at https://doi. org/10.1186/s41938-021-00423-4

Additional file 1: Table S1. Origin of Botrytis cinerea isolates. Table S2. Origin, identification and code accession GenBank of Trichoderma spp. isolated in Algeria. 
Additional file 2: Figure S1. Neighbor-joining phylogenetic tree of Trichoderma spp. constructed with rpb2 sequences. Bootstrap support values higher than $75 \%$ from 1000 replicates are indicated on relevant tree branches. Figure S2. Neighbor-joining phylogenetic tree of Trichoderma spp. constructed with acl1 sequences. Bootstrap support values higher than $75 \%$ from 1000 replicates are indicated on relevant tree branches. Figure S3. Neighbor-joining phylogenetic tree of Trichoderma spp. constructed with ITS sequences. Bootstrap support values higher than $75 \%$ from 1000 replicates are indicated on relevant tree branches.

Additional file 3: Figure S4. Mycelial growth inhibition of $B$. cinerea (BCT04) caused by TGS7 and TAtC11 isolates of Trichoderma spp. revealed by the dual-culture test. Mycelial discs of $B$. cinerea were placed on the right side of the Petri dish. Figure S5. Mycelial growth inhibition of $B$. cinerea (BCT04) caused by volatile compounds produced by TGS7 and TAtC11 isolates.

\section{Acknowledgements}

A tribute to Prof. Meriem Louanchi, who passed away recently. We would like to thank her for her helpful guidance, her relevant assistance and supervision in this scientific research. We will always be grateful for her contribution to the success of this work. We are grateful to IRHS laboratory for hosting us for three months, as well as all the staff for their precise guidelines during the performance of our experiments.

\section{Authors' contributions}

HM carried out surveys, the several experiments, and the writing of the manuscript. GT gave supervision during the internship and revision of the manuscript. AM contributed to the prospection and to the experimentation. BF gave technical contribution in the realization of molecular identifications and biocontrol tests LA technical and scientific assistance in the bioinformatics analysis of the sequence data. LM supervised the research work and revised the article. All authors have read and approved the final manuscript.

\section{Funding}

Not applicable.

\section{Availability of data and materials}

We confirm the availability of all the data included in this study. The fungal material used is available at the laboratory Laboratoire de phytopathologie et de biologie moléculaire, Ecole Nationale Supérieure Agronomique, Algiers, Algeria.

\section{Declarations}

Ethics approval and consent to participate

Not applicable.

\section{Consent for publication}

Not applicable.

\section{Competing interests}

On behalf of all authors, the corresponding author states that there is no conflict of interest.

\section{Author details \\ 'Laboratoire de Phytopathologie et Biologie Moléculaire, Ecole Nationale Supérieure Agronomique (ENSA, ex. INA), Rue Hassan Badi, Belfort, El Harrach, 16004 Algiers, Algeria. ${ }^{2}$ Institut de Recherche en Horticulture et Semences (IRHS), UMR1345, INRA/Agrocampus-Ouest/Université d'Angers, 42 rue Georges Morel, 49071 Beaucouzé Cedex, Angers, France.}

Received: 20 January 2021 Accepted: 26 April 2021

Published online: 14 May 2021

\section{References}

Benítez T, Rincón AM, Limón MC, Codon AC (2004) Biocontrol mechanisms of Trichoderma strains. Int Microbiol. 7(4):249-260

Bissett J, Gams JW, Samuels GJ (2015) Accepted Trichoderma names in the year 2015. IMA fungus 6(2):263-295. https://doi.org/10.5598/imafungus.2015.06.02.02
Carbone I, Kohn LM (1999) A method for designing primer sets for speciation studies in filamentous ascomycetes. Mycologia 91(3):553-556. https://doi. org/10.1080/00275514.1999.12061051

Chen K, Zhuang WY (2017) Discovery from a large-scaled survey of Trichoderma in soil of China. Sci Rep 7(1):1-37. https://doi.org/10.1038/s41598-01707807-3

Core Team R (2020) R: A language and environment for statistical computing. R Foundation for Statistical Computing, Vienna URL https://www.R-project.org/

Dean R, Van Kan JA, Pretorius ZA, Hammond-Kosack KE, Di Pietro A, Spanu PD et al (2012) The Top 10 fungal pathogens in molecular plant pathology. Mol Plant Pathol 13(4):414-430. https://doi.org/10.1111/j.1364-3703.2011.00783.x

Decognet V, Bardin M, Trottin-Caudal Y, Nicot PC (2009) Rapid change in the genetic diversity of Botrytis cinerea populations after the introduction of strains in a tomato glasshouse. Phytopathology 99(2):185-193. https://doi. org/10.1094/PHYTO-99-2-0185

Druzhinina IS, Kopchinskiy AG, Komon M, Bissett J, Szakacs G, Kubicek CP (2005) An oligonucleotide barcode for species identification on Trichoderma and Hypocrea. Fungal Genet Biol 42(10):813-828. https://doi.org/10.1016/j.fgb.2 005.06 .007

Elad Y, Pertot I, Prado AMC, Stewart A (2016) Plant hosts of Botrytis spp. In: Botrytisthe fungus, the pathogen and its management in agricultural systems. Springer, Cham, pp 413-486. https://doi.org/10.1007/978-3-319-23371-0_20

Ezziyyani M, Sánchez CP, Ahmed AS, Requena ME, Castillo MEC (2004). Trichoderma harzianum como biofungicida para el biocontrol de Phytophthora capsici en plantas de pimiento (Capsicum annuum L.). In Anales de biología (No. 26, pp. 35-45). Servicio de Publicaciones de la Universidad de Murcia.

Fillinger S, Ajouz S, Nicot PC, Leroux P, Bardin M (2012) Functional and structural comparison of pyrrolnitrin-and iprodione-induced modifications in the class III histidine-kinase Bos1 of Botrytis cinerea. Plos One 7(8):e42520. https://doi. org/10.1371/journal.pone.0042520

Galarza L, Akagi Y, Takao K, Kim CS, Maekawa N, Itai A, Peralta E, Santos E, Kodama M (2015) Characterization of Trichoderma species isolated in Ecuador and their antagonistic activities against phytopathogenic fungi from Ecuador and Japan. J Gen Plant Pathol 81(3):201-210. https://doi.org/10.1007/s10327015-0587-x

Goodwin DC, Lee SB (1993) Microwave miniprep of total genomic DNA from fungi, plants, protists and animals for PCR. Biotechniques 15(3):438-441

Gräfenhan T, Schroers HJ, Nirenberg HI, Seifert KA (2011) An overview of the taxonomy, phylogeny, and typification of nectriaceous fungi in Cosmospora, Acremonium, Fusarium, Stilbella, and Volutella. Stud Mycol 68:79-113. https:// doi.org/10.3114/sim.2011.68.04

Haouhach S, Karkachi N, Oguiba B, Sidaoui A, Chamorro I, Kihal M, Monte E (2020) Three New Reports of Trichoderma in Algeria: T. atrobrunneum, (South) T. longibrachiatum (South), and T. afroharzianum (Northwest). Microorganisms 8(10):1455

Hermosa R, Viterbo A, Chet I, Monte E (2012) Plant-beneficial effects of Trichoderma and of its genes. Microbiology 158(1):17-25. https://doi.org/10.1 099/mic.0.052274-0

Hmouni A, Hajlaoui MR, Mlaiki A (1996) Résistance de Botrytis cinerea aux benzimidazoles et aux dicarboximides dans les cultures abritées de tomate en Tunisie. EPPO Bull 26(3-4):697-705. https://doi.org/10.1111/j.1365-2338.1 996.tb01513.x

Jaklitsch WM, Komon M, Kubicek CP, Druzhinina IS (2005) Hypocrea voglmayrii sp. nov. from the Austrian Alps represents a new phylogenetic clade in Hypocrea/Trichoderma. Mycologia 97(6):1365-1378. https://doi.org/10.1080/1 5572536.2006 .11832743

Jaklitsch WM, Voglmayr H (2015) Biodiversity of Trichoderma (Hypocreaceae) in Southern Europe and Macaronesia. Stud Mycol 80:1-87. https://doi.org/10.1 016/.simyco.2014.11.001

Joubert A, Calmes B, Berruyer R, Pihet M, Bouchara J, Simoneau P, Guillemette T (2010) Laser nephelometry applied in an automated microplate system to study filamentous fungus growth. Biotechniques 48(5):399-404. https://doi. org/10.2144/000113399

Keddad A, Bouzenad Z (2019) Catalogue des champignons d'Algérie, 2nd edn. Edition TM graphique, Algiers, p 334

Klaiklay S, Rukachaisirikul V, Saithong S, Phongpaichit S, Sakayaroj J (2019) Trichothecenes from a soil-derived Trichoderma brevicompactum. J Nat Products 8(24):687-693. https://doi.org/10.1021/acs.jnatprod.8b00205

Kopchinskiy AG, Komon M, Kubicek CP, Druzhinina IS (2005) TrichoBLAST: A multilocus database for Trichoderma and Hypocrea identifications. Mycol Res 109(6):657-660. https://doi.org/10.1017/s0953756205233397 
Liu YJ, Whelen S, Hall BD (1999) Phylogenetic relationships among ascomycetes: evidence from an RNA polymerse II subunit. Mol Biol Evol 16(12):1799-1808. https://doi.org/10.1093/oxfordjournals.molbev.a026092

Medeiros HA, Araújo Filho JV, Grassi de Freitas L, Castillo P, Rubio MB, Hermosa R et al (2017) Tomato progeny inherit resistance to the nematode Meloidogyne javanica linked to plant growth induced by the biocontrol fungus Trichoderma atroviride. Sci Rep. 7(1):40216. https://doi.org/10.1038/srep40216

Nassr S, Barakat R (2013) Effect of factors on conidium germination of Botrytis cinerea in vitro. Methods 67:68

Nicot PC, Bardin M, Alabouvette C, Köhl J (2011). Potential of biological control based on published research. 1. Protection against plant pathogens of selected crops. In Classical and augmentative biological control against diseases and pests: critical status analysis and review of factors influencing their success. IOBC/WPRS, Zürich, Switzerland, pp 1-11.

Nicot PC, Stewart A, Bardin M, Elad Y (2016) Biological control and biopesticide suppression of Botrytis-incited diseases. In: Botrytis-the Fungus, the Pathogen and its Management in Agricultural Systems. Springer, Cham, pp 165-187. https://doi.org/10.1007/978-3-319-23371-0_9

Olivier JM, Germain R (1983). Etude des antibiotiques volatils des Trichoderma. Pp 17-34. In : " Les antagonismes microbiens. Modes d'action et application à la lutte biologique contre les maladies des plantes ». Bordeaux, mai 1983, Coll. de I'I.N.R.A. $18: 17-34$

Pezet $R$, Pont $V$, Tabacchi $R$ (1999) Simple analysis of 6-pentyl-a-pyrone, a major antifungal metabolite of Trichoderma spp., useful for testing the antagonistic activity of these fungi. Phytochem Anal 10(5):285-288. https://doi.org/10.1 002/(SICl) 1099-1565(199909/10)10:5<285::AID-PCA466>3.0.CO;2-8

Redda ET, Ma J, Mei J, Li M, Wu B, Jiang X (2018) Antagonistic potential of different isolates of Trichoderma against Fusarium oxysporum, Rhizoctonia solani, and Botrytis cinerea. Eur J Exp Biol 8(2):12

Samuels G, Hebbar P (2015) Trichoderma identification and agricultural applications. American Phytopathological Society Press, St. Paul, p 196

Schüepp H, Küng M (1978) Souches de Botrytis cinerea tolérantes aux fongicides de type imide cyclique. Ber schweiz Dot Ges. 88:63-71

Shao W, Zhao Y, Ma Z (2021). Advances in understanding fungicide resistance in Botrytis cinerea in China. Phytopathology", PHYTO-07. doi:https://doi.org/10.1 094/PHYTO-07-20-0313-IA

Shentu X, Zhan X, Ma Z, Yu X, Zhang C (2014) Antifungal activity of metabolites of the endophytic fungus Trichoderma brevicompactum from garlic. Braz J Microbiol 45(1):248-254. https://doi.org/10.1590/S1517-83822014005000036

Sood M, Kapoor D, Kumar V, Sheteiwy MS, Ramakrishnan M, Landi M et al (2020) Trichoderma: the "secrets" of a multitalented biocontrol agent. Plants 9(6): 762. https://doi.org/10.3390/plants9060762

Verma M, Brar SK, Tyagi RD, Surampalli RY, Valero JR (2007) Antagonistic fungi, Trichoderma spp.: panoply of biological control. Biochem Eng J 37(1):1-20. https://doi.org/10.1016/j.bej.2007.05.012

Vignutelli A, Hilber-Bodmer M, Hilber UW (2002) Genetic analysis of resistance to the phenylpyrrole fludioxonil and the dicarboximide vinclozolin in Botryotinia fuckeliana (Botrytis cinerea). Mycol Res 106(3):329-335. https://doi.org/10.101 7/S0953756202005683

Vinale F, Sivasithamparam K, Ghisalberti EL, Marra R, Woo SL, Lorito M (2008) Trichoderma-plant-pathogen interactions. Soil Biol Biochem 40(1):1-10. https://doi.org/10.1016/j.soilbio.2007.07.002

White TJ, Bruns T, Lee SJWT, Taylor J (1990) Amplification and direct sequencing of fungal ribosomal RNA genes for phylogenetics. PCR Protoc 18(1):315-322

Williamson B, Tudzynski B, Tudzynski P, Van Kan JA (2007) Botrytis cinerea: the cause of grey mould disease. Mol Plant Pathol 8(5):561-580. https://doi.org/1 0.1111/j.1364-3703.2007.00417.x

Xue QY, Chen Y, Li SM, Chen LF, Ding GC, Guo DW, Guo JH (2009) Evaluation of the strains of Acinetobacter and Enterobacter as potential biocontrol agents against Ralstonia wilt of tomato. Biol Control 48(3):252-258. https://doi.org/1 0.1016/j.biocontrol.2008.11.004

You J, Zhang J, Wu M, Yang L, Chen W, Li G (2016) Multiple criteria-based screening of Trichoderma isolates for biological control of Botrytis cinerea on tomato. Biol Control 101:31-38. https://doi.org/10.1016/j.biocontrol.2016.06.006

\section{Publisher's Note}

Springer Nature remains neutral with regard to jurisdictional claims in published maps and institutional affiliations.

\section{Submit your manuscript to a SpringerOpen ${ }^{\circ}$ journal and benefit from:}

- Convenient online submission

- Rigorous peer review

- Open access: articles freely available online

- High visibility within the field

- Retaining the copyright to your article

Submit your next manuscript at $\boldsymbol{\nabla}$ springeropen.com 